\title{
Enhanced Photocatalytic Degradation of Bisphenol A in Aqueous Solution by Ag-Doping ZnO
}

\author{
Nobuyuki Hoshiyama1, Ahmed H. A. Dabwan², Hideyuki Katsumata1, Tohru Suzuki³, \\ Mai Furukawa', Satoshi Kaneco1,3 \\ ${ }^{1}$ Department of Chemistry for Materials, Graduate School of Engineering, Mie University, Mie, Japan \\ ${ }^{2}$ Faculty of Chemical Engineering Technology, Tati University College, Kemaman, Malaysia \\ ${ }^{3}$ Mie Global Environment Center for Education \& Research, Mie University, Mie, Japan \\ Email:kaneco@chem.mie-u.ac.jp
}

Received 30 March 2016; accepted 27 June 2016; published 30 June 2016

Copyright (C) 2016 by authors and Scientific Research Publishing Inc.

This work is licensed under the Creative Commons Attribution International License (CC BY). http://creativecommons.org/licenses/by/4.0/

(c) (i) Open Access

\section{Abstract}

The metal-doping into the photocatalyst was evaluated for the photocatalytic degradation of bisphenol $\mathrm{A}$ in aqueous solution with $\mathrm{ZnO}$ powder. $\mathrm{Au} / \mathrm{ZnO}, \mathrm{Ag} / \mathrm{ZnO}$ and $\mathrm{Cu} / \mathrm{ZnO}$ were tested in the present work. Ag-doping $\mathrm{ZnO}$ was effective for the improvement of efficiency for the photocatalytic degradation of bisphenol $A$ in water. The optimum doping concentration of silver was found to be $3 \mathrm{wt} \%$. The pseudo first-order rate constant with $3 \mathrm{wt} \% \mathrm{Ag} / \mathrm{ZnO}$ was 1.3 times better compared with bare $\mathrm{ZnO}$. The photocatalytic degradation of treatment for the wastewater containing bisphenol $A$ is simple, easy handling and low cost.

\section{Keywords}

ZnO, Ag-Doping, Bisphenol A, Wastewater Treatment, Photocatalytic Degradation

\section{Introduction}

Recently, a wide variety of chemicals that have been pointed out to disrupt endocrine system of higher life forms, such as fish, wildlife and even humans, have attracted considerable attentions worldwide [1]. Although it is still being discussed whether such chemicals have an enormous influence upon human beings or not, it is necessary to develop technology for their elimination.

Bisphenol A (BPA), that is, 4, 4-isopropylidenediphenol is manufactured in high quantities, 90\% or more being used as a monomer for the production of polycarbonate (PC) and epoxy resins, unsaturated polyester-styrene 
resins and flame retardants. The final products are used as coatings on cans, as powder paints, as additives in thermal paper, in dental fillings and as antioxidants in plastics [2]. It is well-understood that BPA has an estrogenic activity, namely, it serves as an environmental endocrine disruptor [3]. The dispersion into the natural environment and into surface water is possible in the manufacturing processes and by leaching from final products. Therefore, it is very significant to develop the treatment technology for BPA rapidly.

Some researchers [4] [5] have reported the photocatalytic degradation of $\mathrm{BPA}$ in a $\mathrm{TiO}_{2}$ aqueous suspension. First, we have investigated the photodegradation system of BPA in aqueous $\mathrm{TiO}_{2}$ suspension under sunlight illumination [6]. In the photocatalytic degradation system, BPA could be degraded in aqueous $\mathrm{TiO}_{2}$ dispersion under sunlight illumination. Next, we have studied the solar photocatalytic degradation of BPA in the aqueous $\mathrm{ZnO}$ suspension [7] [8]. The greatest advantage of $\mathrm{ZnO}$ is that it absorbs larger fraction of the solar spectrum than $\mathrm{TiO}_{2}$. Despite demonstration of possible degradation of BPA with $\mathrm{ZnO}$, there are few reports concerning the photocatalytic degradation of BPA with metal-doping $\mathrm{ZnO}$.

Accordingly, the present study investigates the photocatalytic degradation of BPA in aqueous solution with Ag-doping ZnO.

\section{Experimental}

\subsection{Fabrication of Metal-Doped ZnO}

$\mathrm{ZnO}$ nanopowders used in the present work were purchased from Sigma-Aldrich Co. (specific surface area: 15 $25 \mathrm{~m}^{2} / \mathrm{g}$, mean particle size: $50-70 \mathrm{~nm}$ ). The $\mathrm{ZnO}$ nanopowders were put into $100 \mathrm{~mL}$ of $\mathrm{NaBH}_{4}$ solution (5 $\mathrm{mg} / \mathrm{mL}$ ), and then $100 \mathrm{~mL}$ of metal solution with a given concentration was slowly added into the $\mathrm{ZnO}$ suspension dropwise. The $\mathrm{ZnO}$ suspension was centrifuged at $4000 \mathrm{rpm}$ for $5 \mathrm{~min}$. After the supernatant solution was removed by the pipette, the metal-doped $\mathrm{ZnO}$ was dried in a vacuum drying oven (AS ONE Corp., AVO-200NB) for more than 24 hours.

\subsection{Photocatalytic Degradation}

BPA $(10 \mu \mathrm{g} / \mathrm{mL})$ aqueous solutions were prepared with ultrapure water. Laboratory ultrapure water was obtained from an ultrapure Advantac RDF 260 water system with high purity ion exchanged water (Advantec MFS Inc., Tokyo, Japan) resulting in a resistivity $>18 \mathrm{M} \Omega \cdot \mathrm{cm}$. Then, a $30 \mathrm{~mL}$ aqueous solution containing $10 \mu \mathrm{g} / \mathrm{mL}$ $(0.044 \mu \mathrm{M}) \mathrm{BPA}$ was put into a Pyrex glass reaction vessel (30 mL capacity). The photocatalyst powder was added into the solution to produce a $1.67 \mathrm{mg} / \mathrm{mL}$ of suspension concentration. The experimental conditions for the degradation treatment were shown in Table 1.

A xenonlamp (500 W, UXL-500D-O) was applied as light source, which was positioned on the side of photoreactor. The IR cutoff filter (>750 nm, HA-50, HOYA) was used for the ultraviolet and visible light illumination. The light intensity was measured by a UV radio meter with a sensor of 320 - $410 \mathrm{~nm}$ wavelengths (UVR-400, Iuchi Co., Osaka, Japan), and the value was $0.055 \mathrm{~mW} / \mathrm{cm}^{2}$. The photocatalysts were continuously dispersed in the aqueous solution by a magnetic stirrer during the irradiation.

After the illumination, the photocatalyst was separated by centrifugation, and the BPA concentration in the solution was determined by high-performance liquid chromatograph with TSK gel ODS-100V column (Tosoh Corp.) The elution was monitored at $276 \mathrm{~nm}$. The eluent used was a mixed solvent of acetonitrile and water (1:1, $\mathrm{v} / \mathrm{v}$ ). The flow rate of the mobile phase was $1.5 \mathrm{~mL} / \mathrm{min}$.

Table 1. Degradation conditions.

\begin{tabular}{cc}
\hline BPA & $10 \mu \mathrm{g} / \mathrm{mL}, 30 \mathrm{~mL}$ \\
Photocatalyst & $\mathrm{ZnO}, \mathrm{Ag} / \mathrm{ZnO}, \mathrm{Au} / \mathrm{ZnO}, \mathrm{Cu} / \mathrm{ZnO}$ \\
Photocatalyst dosage & $50 \mathrm{mg} / 30 \mathrm{~mL}$ \\
Temperature & $25^{\circ} \mathrm{C}$ \\
Initial pH of solution & 8 \\
Light intensity & $0.055 \mathrm{~mW} / \mathrm{cm}^{2}$ \\
\hline
\end{tabular}




\section{Results and Discussion}

In the primary experiments [7] [8], the solar photocatalytic degradation conditions of BPA in an aqueous solution were optimized. As a consequence, the BPA in the aqueous solution almost completely disappeared and was degraded in $300 \mathrm{~min}$, working with moderate amounts of $\mathrm{ZnO}$ under sunlight illumination. Therefore, the metal doping effect was tested on the photocatalytic degradation of BPA.

\subsection{Effect of Metal Doping}

First, the effect of metal doping into the photocatalyst was investigated on the photocatalytic degradation of $\mathrm{BPA}$ in water with $\mathrm{ZnO}$ powders. The $\mathrm{Au}, \mathrm{Ag}$, and $\mathrm{Cu}$-doped $\mathrm{ZnO}$ were evaluated in the present work. The results are shown in Figure 1. The degradation efficiencies with gold and copper-doped $\mathrm{ZnO}$ were worse compared with those obtained with bare $\mathrm{ZnO}$. However, the silver-deposited $\mathrm{ZnO}$ was very effective for the improvement of photocatalytic degradation of BPA in aqueous solution. BPA was completely degraded by the photocatalytic degradation with bare $\mathrm{ZnO}$ on 60 min of irradiation time; on the other hand, the BPA disappeared on the 45 min irradiation.

\subsection{Effect of Silver Doping Concentration}

Since it was found that the silver deposition into $\mathrm{ZnO}$ photocatalyst was very effective for improvement of photocatalytic degradation of BPA in aqueous solution, the silver doping concentration with $1 \mathrm{wt} \%$ to $5 \mathrm{wt} \%$ was evaluated for the BPA degradation.

The photocatalytic degradation of various organic compounds by means of illuminated $\mathrm{ZnO}$ can be estimated to follow a pseudo first-order kinetic law, according to the equation,

$$
\frac{\mathrm{d} C_{\text {subs }}}{\mathrm{d} t}=-k_{\text {obs }} C_{\text {subs }}
$$

where $C_{\text {subs }}$ is the BPA concentration and $k_{\text {obs }}$ is the observed first-order rate constant. It was concluded in the previous work that the primary photocatalytic decomposition reaction follows a pseudo first-order kinetic laws. Therefore, in order to estimate the pseudo first-order rate constant, $\mathrm{Ln}\left(\mathrm{C} / \mathrm{C}_{0}\right)$ was plotted as a function of the illumination time. Figure 2 shows the comparison between bare $\mathrm{ZnO}$ and silver deposited-ZnO (3 wt\% and 4 wt\%) The value $k_{o b s}$ in the case of photocatalyst with bare $\mathrm{ZnO}$ was $0.044 \mathrm{~min}^{-1}$. However, the value $k_{o b s}$ with silver-deposited $\mathrm{ZnO}$ was 0.058 and $0.047 \mathrm{~min}^{-1}$ for $3 \mathrm{wt} \%$ and $4 \mathrm{wt} \%$ doping amount, respectively. Therefore, the pseudo first-order rate constant using $3 \mathrm{wt} \% \mathrm{Ag} / \mathrm{ZnO}$ was 1.3 times larger relative to bare $\mathrm{ZnO}$. The firstorder rate constant with $4 \mathrm{wt} \% \mathrm{Ag} / \mathrm{ZnO}$ was worse relative to that with $3 \mathrm{wt} \% \mathrm{Ag}$ because the photocatalytic activity became poor in the large coverage of silver on the $\mathrm{ZnO}$ surface.

\subsection{Reaction Mechanism}

In the semiconductor $\mathrm{Ag} / \mathrm{TiO}_{2}$ photocatalyst with a band gap $\mathrm{E}_{\mathrm{g}}$, upon the illumination with radiation having an energy greater relative or equal to the band gap $E_{g}$, the promotion of an electron ( $e^{-}$) from the valance band (VB)

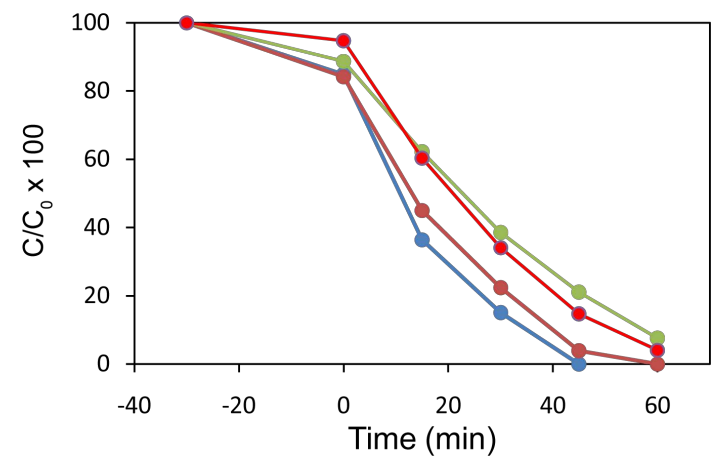

Figure 1. Effect of Ag doping on the photocatalytic degradation of BPA with $\mathrm{ZnO}$ in aqueous solution. Brown: bare $\mathrm{ZnO}$, blue: $\mathrm{Ag} / \mathrm{ZnO}$, red: $\mathrm{Cu} / \mathrm{ZnO}$, green: $\mathrm{Au} / \mathrm{ZnO}$. 


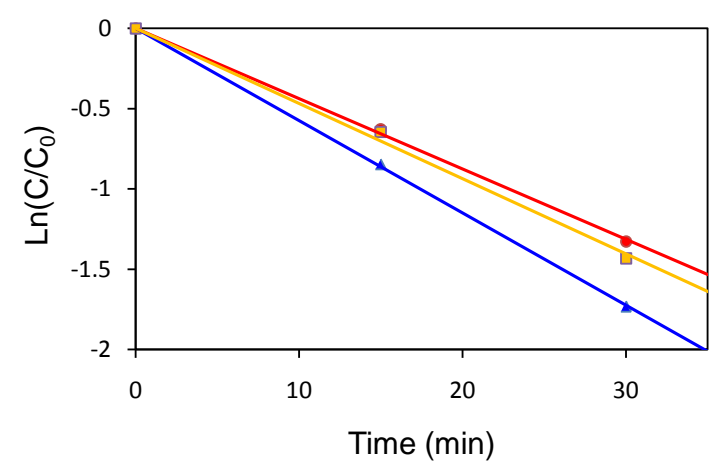

Figure 2. Effect of Ag doping concentration on the photocatalytic degradation of BPA with bare and Ag/ZnO in aqueous solution. Circle: bare $\mathrm{ZnO}$, triangle: 3 wt\% Ag/ZnO, square: 4 wt\% Ag/ZnO.

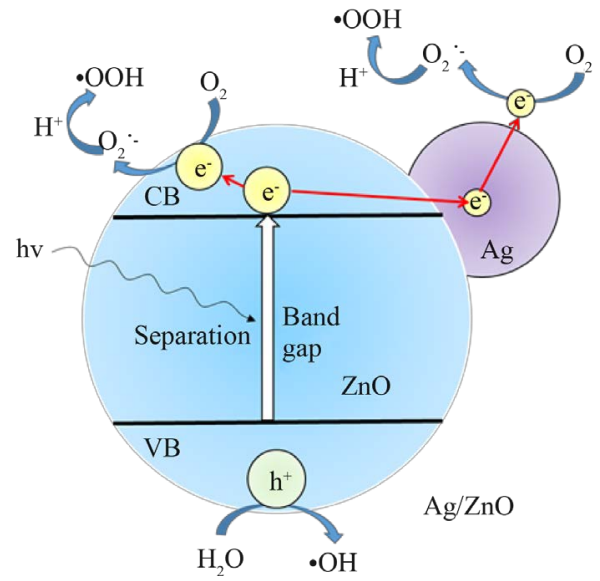

Figure 3. Reaction mechanism for the photocatalytic degradation of BPA with Ag/ZnO.

to the conduction band (CB) takes place. Concomitantly, the formation of a positive hole $\left(\mathrm{h}^{+}\right)$in the VB occurs. Photogenerated electrons and holes can either undergo undesired recombination/or migrate to the surface of the system, where they can initiate reactions with adsorbed species. Whereas holes in the VB are powerful oxidizing species that can produce hydroxyl radicals $(\cdot \mathrm{OH})$ from the reaction with $\mathrm{H}_{2} \mathrm{O}$, photogenerated electrons in the $\mathrm{CB}$ are involved in the formation of $\bullet \mathrm{OOH}$. These oxidizing species may attack the pollutant BPA in the aqueous solution. The presence of the Schottky barrier can decrease the recombination of photogenerated electron-hole pairs consequently prolong their lifetime, and greatly enhance the photocatalytic activity of $\mathrm{ZnO}$. Silver loading can result in stronger Schottky barrier effect, and therefore shows better photocatalytic activity of $\mathrm{ZnO}$, as illustrated in Figure 3 [9].

\section{Conclusion}

The silver-doping $\mathrm{ZnO}$ photocatalyst was more efficient for the photocatalytic degradation of BPA in aqueous solution. The optimal doping concentration of silver was $3 \mathrm{wt} \%$. The primary photocatalytic decomposition reaction with Ag-doping $\mathrm{ZnO}$ follows a pseudo first-order kinetic law. It was concluded that the pseudo first-order rate constant with $3 \mathrm{wt} \% \mathrm{Ag} / \mathrm{ZnO}$ was 1.3 times larger relative to bare $\mathrm{ZnO}$. Since Ag-doping $\mathrm{ZnO}$ photocatalyst is a cheap material, the water treatment system developed is rapid, simple and inexpensive for the removal of bisphenol A.

\section{Acknowledgements}

The present research was partly supported by Grant-in-Aid for Scientific Research (C) 15K00602 from the Ministry of Education, Culture, Sports, Science, and Technology of Japan. All experiments were conducted at Mie University. Any opinions, findings, conclusions or recommendations expressed in this paper are those of the 
authors and do not necessarily reflect the view of the supporting organizations.

\section{References}

[1] Harries, J.E., Runnalls, T., Hill, E., Harris, C.A., Maddix, S., Sumpter, J.P. and Tyler, C.R. (2000) Development of a Reproductive Performance Test for Endocrine Disrupting Chemicals Using Pair-Breeding Fathead Minnows (Pimephalespromelas). Environmental Science \& Technology, 34, 3003-3011. http://dx.doi.org/10.1021/es991292a

[2] Staples, C.A., Dome, P.B., Klecka, G.M., Oblock, S.T. and Harris, L.R. (2002) A Review of the Environmental Fate, Effects, and Exposures of Bisphenol A. Chemosphere, 36, 2149-2173. http://dx.doi.org/10.1016/S0045-6535(97)10133-3

[3] Krishnan, A.V., Stathis, P., Permuth, S.F., Tokes, L. and Feldman, D. (1993) Bisphenol-A: An Estrogenic Substance Is Released from Polycarbonate Flasks during Autoclaving. Endocrinology, 132, 2279-2286.

[4] Luo, L., Yang, Y., Xiao, M., Bian, L., Yuan, B., Liu, Y., Jiang, F. and Pan, X. (2015) A Novel Biotemplated Synthesis of $\mathrm{TiO}_{2}$ /Wood Charcoal Composites for Synergistic Removal of Bisphenol A by Adsorption and Photocatalytic Degradation. Chemical Engineering Journal, 262, 1275-1283. http://dx.doi.org/10.1016/j.cej.2014.10.087

[5] Doong, R. and Tsai, C. (2015) Synergistic Effect of Cu Adsorption on the Enhanced Photocatalytic Degradation of Bisphenol A by $\mathrm{TiO}_{2} /$ Titanate Nanotubes Composites. Journal of the Taiwan Institute of Chemical Engineers, 57, 69-76. http://dx.doi.org/10.1016/j.jtice.2015.05.013

[6] Kaneco, S., Rahman, M.A., Suzuki, T., Katsumata, H. and Ohta, K. (2005) Optimization of Solar Photocatalytic Degradation Conditions of Bisphenol A in Water Using Titanium Dioxide. Journal of Photochemistry and Photobiology A: Chemistry, 163, 419-424. http://dx.doi.org/10.1016/j.jphotochem.2004.01.012

[7] Rahman, M.A., Kaneco, S., Suzuki, T., Katsumata, H. and Ohta, K. (2004) Solar Photocatalytic Degradation of Bisphenol A in Water with ZnO. Photo/Electrochemistry \& Photobiology in the Environment, Energy and Fuel, 3, 199205.

[8] Rahman, M.A., Kaneco, S., Suzuki, T., Katsumata, H. and Ohta, K. (2004) Optimized Conditions for the Solar Photocatalytic Degradation of Bispehnol A in Water with Zinc Oxide. Annali di Chimica, 95, 715-719. http://dx.doi.org/10.1002/adic.200590083

[9] Takai, A. and Kamat, P.V. (2011) Capture, Store, and Discharge. Shuttling Photogenerated Electrons across $\mathrm{TiO}_{2}$-Silver Interface. ACS Nano, 5, 7369-7376. http://dx.doi.org/10.1021/nn202294b

\section{Submit or recommend next manuscript to SCIRP and we will provide best service for you:}

Accepting pre-submission inquiries through Email, Facebook, Linkedin, Twitter, etc A wide selection of journals (inclusive of 9 subjects, more than 200 journals)

Providing a 24-hour high-quality service

User-friendly online submission system

Fair and swift peer-review system

Efficient typesetting and proofreading procedure

Display of the result of downloads and visits, as well as the number of cited articles

Maximum dissemination of your research work

Submit your manuscript at: http://papersubmission.scirp.org/ 